\title{
Clinical study of paediatric dermatoses
}

\author{
Dr.t.v.narasimha rao $^{1}$, Dr.lohitha ${ }^{2}$, dr.g.purnima ${ }^{3}$, Dr.t.s.p kumar ${ }^{4}$, \\ Dr.e.haribabu ${ }^{5}$.
}

Dept. of DVL, Siddhartha Medical College, Vijayawada, Andhra Pradesh, India.

\begin{abstract}
:
Background: Pediatric dermatoses are distinct group of disorders, comprising of skin problems encountered during childhood and adolescence. There is variation in the pattern and presentation of dermatoses in childhood compared to adults
\end{abstract}

Aim: To ascertain the pattern of various dermatoses occurring in children aged below 12 years attending the Department of DVL, Government general hospital, Vijayawada, Andhra Pradesh. .

Methodology: This was a cross sectional, clinical observational study in pediatric patients attending DVL OPD of tertiary care centre Vijayawada between July 2013 - June2014, were enrolled in the present study.

Results: Among 500 patients the most common age group is 4-6 yrs (39\%) followed by 7-9 yrs (32\%). Sex ratio in our study is 1.27:1(M: F). Common disease observed is infections $32 \%$, followed by Infestations $21 \%$, Eczemas 14\%, hypersensitivity disorders 9\%. Pigmentary disorders 4\%, Sweat and sebaceous gland disorders $3.82 \%$, Papulosquamous disorders 2.8\%, Nutritional disorders 2.7\%, Keratinization disorders $2.4 \%$, Photodermatoses 2.3\%, Nevi and Nevoid disorders 2\%, Disorders of Hair and Nail $1.5 \%$.

Conclusion: The present study brings out the unique features of Tropical pediatric dermatology. The incidence of pediatric dermatoses can be brought down by increasing awareness among the population regarding etiology and spread of pediatric diseases and by improving sanitation, nutrition and personal hygiene of children.

Key words: Infections in Childhood, Pediatric Dermatoses.

\section{I . Introduction}

Pediatric dermatoses are distinct group of disorders, comprising of skin problems encountered during childhood and adolescence ${ }^{1}$. Skin diseases in the pediatric population are common all over the world. There is variation in the pattern and presentation of dermatoses, with eczemas being the most common skin disorder in developed countries and infections and infestations in the developing countries. The incidence of pediatric dermatological conditions is on a gradual increase day by day. Dermatoses in children are more influenced by socioeconomic status, climatic exposure, dietary habits and external environment as compared to dermatoses in adults.

Dermatologic conditions constitute at least $30 \%$ of all outpatient visits to pediatricians, and $30 \%$ of all visits to dermatologists involve children ${ }^{2,3}$. The frequency of pediatric dermatoses in school based surveys in India has ranged from $8.7 \%$ to $35 \%{ }^{4}$. Cutaneous infections are common in children during school going years due to the fact that they are exposed to subclinical infectious cases by intermingling with each other.

The aim of the present study is to determine the pattern of common dermatoses in children attending the Government General Hospital, Vijayawada, Andhra Pradesh. The present study brings into light the unique features of Tropical pediatric dermatoses.

\section{Aim}

1.To ascertain the pattern of various dermatoses occurring in children aged below 12 years attended the Department of DVL, GGH Vijayawada.

2.To determine the possible factors that contribute to pediatric dermatoses.

\section{Patients \& methods}

Study was conducted on 500 children with dermatoses aged below 12 years attending the Dept.of D.V.L, Govt.General Hospital, Vijayawada.It was a hospital based cross sectional and clinical observational study conducted between July 2013 to June 2014. Informed valid written consent was taken from parents and clinical data was recorded as per the proforma. Detailed history taken and complete clinical examination was done. All these patients were subjected to routine investigations and special investigations were done whenever necessary. 


\section{Observations \& results}

500 randomly selected children attending the DVL department Government general hospital, Vijayawada from 1.7.2013 to 30.6.2014 were studied and analyzed as follows.

1.Sex distribution:

Table No: $1(\mathrm{n}=500)$

\begin{tabular}{|c|c|c|}
\hline Out Patients & Number & Percentage \\
\hline Male Children & 280 & 56 \\
\hline Female Children & 220 & 44 \\
\hline Total & 500 & 100 \\
\hline
\end{tabular}

In the present study, male children constituted about 56\% (280) and female children constituted about $44 \%(220)$.

\section{Age distribution:}

Table No: $2(\mathrm{n}=500)$

\begin{tabular}{|c|c|c|}
\hline Age Of Children & No. Of Children & Percentage \\
\hline Birth To 3 Years & 110 & 22 \\
\hline 4 To 6 Years & 195 & 39 \\
\hline 7 To 9 Years & 160 & 32 \\
\hline 10 -12 Years & 35 & 7 \\
\hline
\end{tabular}

In the present study, maximum number of children belonged to age group 4 to 6 years, making up 39\% (195) of the total. Children in the age group 7 to 9 years constituted the next common group making 32\% (160). Children belonging to the age group 0 to 3 years constituted $22 \%$ (110). The least number of children during the study period belonged to 10 to 12 years, comprising $7 \%$ (35) of total children.

\section{Socio Economic Status:}

Table No: $3(\mathrm{n}=500)$

\begin{tabular}{|c|c|c|}
\hline Socioeconomic Status & Number & Percentage \\
\hline Lower Class & 360 & 72 \\
\hline Lower Middle Class & 65 & 13 \\
\hline Upper Middle Class & 50 & 10 \\
\hline Upper Class & 25 & 5 \\
\hline Total & 500 & 100 \\
\hline
\end{tabular}

In the present study, Socioeconomic background was taken into account. It showed that $72 \%$ (360) of them belonged to the lower socioeconomic sector. 13\% (65) belonged to the lower middle class, while 10\% (50) belonged to the upper middle class. It was observed that only 5\% (25) of these children belonged to the upper class.

\section{Distribution of Pediatric Dermatoses:}

Table No:5 $(\mathrm{n}=500)$

\begin{tabular}{|c|l|c|c|}
\hline S.No & \multicolumn{1}{|c|}{ Disease } & Number & Percentage \\
\hline 1 & Infections & 160 & 32 \\
\hline 2 & Infestations & 105 & 21 \\
\hline 3 & Eczemas & 69 & 13.8 \\
\hline 4 & Hypersensitivity Disorders & 47 & 9.39 \\
\hline 5 & Pigmentary Disorders & 20 & 4 \\
\hline \multirow{2}{*}{6} & Disorders Of Sweat And Sebaceous & 19 & 3.82 \\
\hline 7 & Glands & 14 & 2.8 \\
\hline 8 & Napulosquamous Disorders & 13 & 2.7 \\
\hline 9 & Keratinization Disorders & 12 & 2.4 \\
\hline 10 & Photodermatoses & 11 & 2.3 \\
\hline 11 & Nevi And Nevoid Disorders & 10 & 2 \\
\hline 12 & Disorders Of Hair And Nail & 8 & 1.5 \\
\hline 13 & Miscellaneous & 5 & 0.89 \\
\hline 14 & Vesiculobullous Disorders & 3 & 0.6 \\
\hline 15 & Connective Tissue Diseases And & 3 & 0.6 \\
\hline
\end{tabular}




\begin{tabular}{|c|c|c|c|}
\hline & Disorders & & \\
\hline 16 & Genodermatoses & 1 & 0.2 \\
\hline & Total & 500 & 100 \\
\hline
\end{tabular}

In the present study, different types of cutaneous lesions seen in children were categorized according to the etiology. Infections were the commonest cause of various dermatoses. It constituted 32\% (160). Infestations were next common group observed making up to $21 \%$ (105), Eczemas were the third common dermatoses seen. They constituted about $13.8 \%$ (69). Hypersensitivity disorders constituted fourth position. They accounted for about $9.39 \%$ (47). This was followed by Pigmentary disorders. It constituted about $4 \%$ (20). Disorders of sweat and sebaceous glands were seen in about $3.82 \%$ (19).

Papulosquamous diseases were seen in about $2.8 \%$ (14), Nutritional disorders were seen in $2.7 \%(13)$, keratinization disorders in 2.4\% (12), Photodermatoses in 2.3\% (11), Nevi and nevoid defects in 2\% (10), Disorders of Hair and nails in $1.5 \%$ (8), Vesiculobullous diseases in $0.6 \%$ (3), Connective tissue diseases and disorders in $0.6 \%$ (3), Genodermatoses in $0.2 \%$ (1), Miscellaneous in $0.89 \%$ (5).
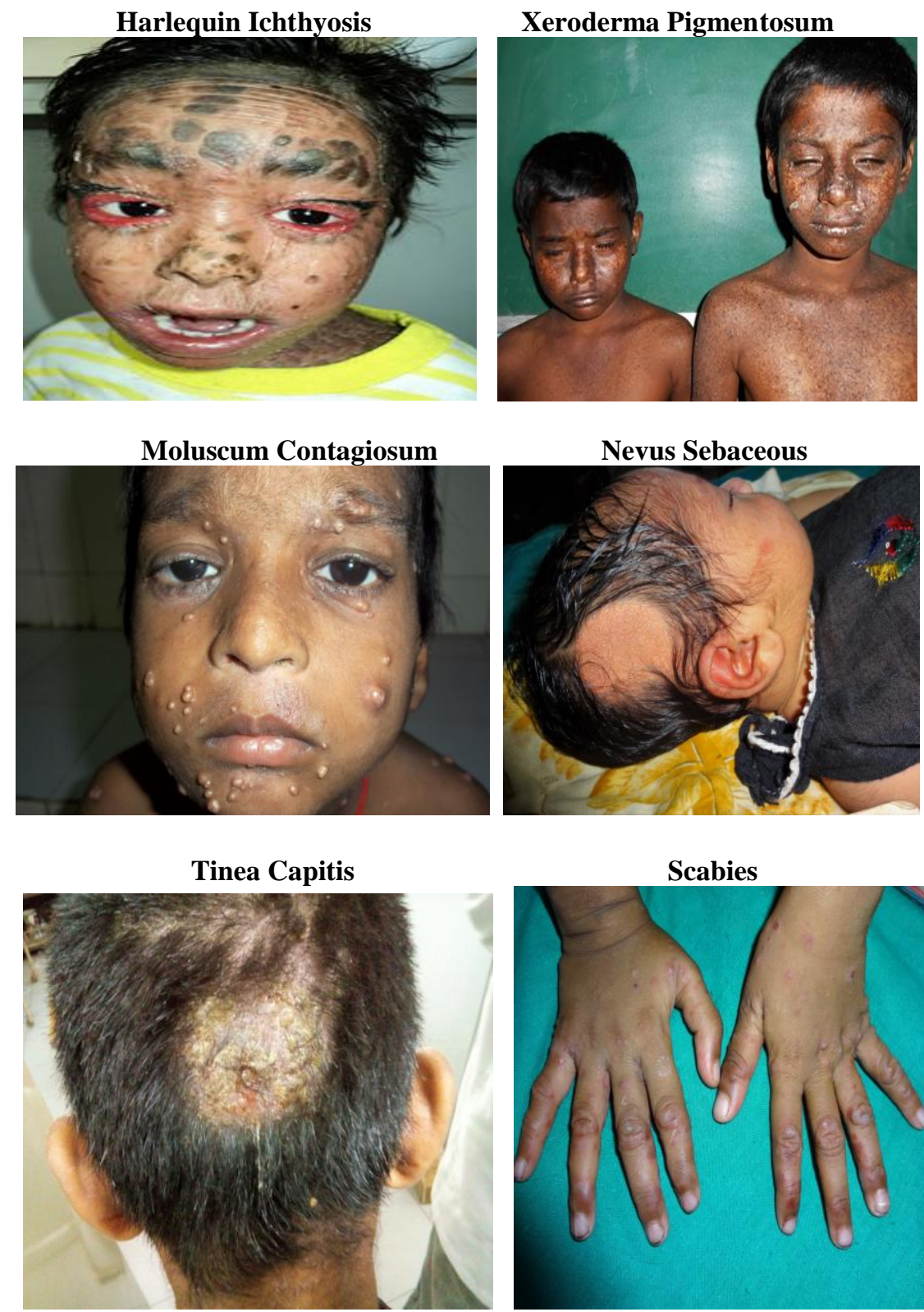

Warts

Epidermolysis Bullosa 

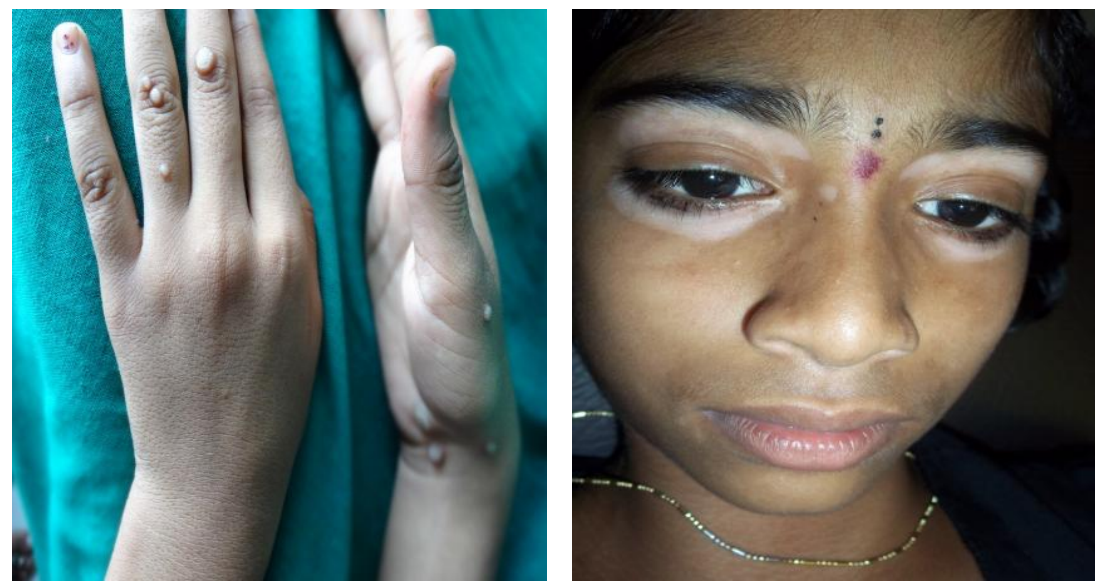

\section{Discussion}

In Present study males constituted about 56\% (280) cases and females constituted about 44\% (220) cases. Males outnumbered females. In present study, Male to female ratio is about 1.27:1. In a study done by M. D. Al-Mendalawi et al ${ }^{5}$., Male: female ratio was 1.29:1, which is in correlation with the present study. In study conducted by M. D. Al-Mendalawi et $\mathrm{al}^{5}$, Rita Vora et $\mathrm{al}^{6}$, Iffat Hassan et $\mathrm{al}^{7}$., S.Sacchidanand et al ${ }^{8}$, have found males more than females, similar to the present study.

In present study, Infections and Infestations were the commonest dermatoses in children that accounted for $53 \%$.In a study conducted by Kaliaperumal Karthikeyan et $\mathrm{al}^{9}$, at JIPMER Pondicherry, Infections and Infestations constituted about $54.5 \%$, which is in correlation with the present study. Sardana $\mathrm{K}$ et $\mathrm{al}^{16}$

showed $47.5 \%$, Manisha Balai et $\mathrm{al}^{10}$ showed $40.6 \%$. Compared to various other studies mentioned above, higher frequency of Infections and Infestations in present study could be possibly due to large number of population attending the department are of low socio-economic group, who were associated with low hygienic conditions.

In the present study Bacterial infections constituted about $52 \%$ of the total Infections. The pattern of bacterial infections found in the present study is in correlation with the study done by Manisha Balai et $\mathrm{al}^{10} \mathrm{In}$ present study, Impetigo was common among preschool and school age children which is consistent with the study of Iffat Hassan et al ${ }^{7}$. Fungal infections constituted about $24 \%$ of all infections in our study. In a study done by Iffat Hassan et $\mathrm{al}^{7}$, Kaliaperumal Karthikeyan et $\mathrm{al}^{9}$ and M.D. Al-Mendalawi et al ${ }^{5}$, have found similar pattern of fungal infections, which is in correlation with the present study. In present study, Warts were the most common viral infection followed by Molluscum contagiosum(MC). In study conducted by M. D. Al-Mendalawi et $\mathrm{al}^{5}$ and RitaVora et $\mathrm{al}^{6}$, warts are the most common viral infection which is followed by MC, which is consistent with the present study.

The Incidence of Infestations was found to be $21 \%$ in present study and it included scabies and Pediculosis. Scabies alone constituted majority of this, making $75 \%$ of infestations, which is making around $16 \%$ of total dermatoses. Kaliaperumal Karthikeyan et $\mathrm{al}^{9}$,in his study observed $14.2 \%$ of scabies, which is in correlation with the present study. In present study, Pediculosis constituted about $25 \%$ of the infestations and $5 \%$ of total cases. In a study conducted by M. D. Al-Mendalawi et $\mathrm{al}^{5}$, the frequency of pediculosis was found to be $3.6 \%$ which is almost near to the present study. An epidemiologic study from Garhwal ${ }^{15}$, Uttar Pradesh, showed that pediculosis capitis $(22.6 \%)$ was the most common dermatoses, being three times more common in girls.

Eczemas constituted the third common group of dermatoses in the present study. It is seen in about $13.8 \%$. In a study conducted by Dogra et al ${ }^{18}$, Eczemas constituted about $13.8 \%$, which is in correlation with present study. Atopic dermatitis was the commonest eczema seen in the present study. It constituted about $36 \%$ of total eczemas and $5 \%$ of all dermatoses. In a study by Al-Mendalawi et $\mathrm{al}^{5}$ and Manisha Balai et $\mathrm{al}^{10}$, Atopic dermatitis was the most common eczematous dermatitis similar to present study. In a study conducted by Sardana $\mathrm{K}$ et $\mathrm{al}^{16}$ atopic dermatitis was seen in $5.2 \%$, which is consistent with the present study. In a study conducted by Saurabh sharma et $\mathrm{al}^{11}$, atopic dermatitis was seen $3.4 \%$. Pityriasis alba was the second most common eczematous dermatoses seen in present study. It constituted about $23 \%$ of all eczemas and $3.2 \%$ of all cases. . In a study conducted by Rita vora et $\mathrm{a}^{6}$, Pityriasis alba constituted about $21.86 \%$, which is in correlation with the present study. Seborrheic dermatitis was the third common eczematous dermatoses in the present study. It constituted about $17 \%$ of all eczematous conditions and $2.4 \%$ of all dermatoses.

In the present study, Hypersensitivity reactions constituted about fourth common dermatoses. It constitutes about $9.39 \%$. This is consistent with study of Iffat Hassan et $\mathrm{al}^{7}$., and Sardana $\mathrm{K}$ et al ${ }^{12}$ In the present study papular urticaria was the most common hypersensitivity disorder seen. It constitutes about $76 \%$ of 
hypersensitivity reactions and about $7.2 \%$ of all dermatoses. In a study done by Iffat Hassan et $\mathrm{al}^{7}$, papular urticaria constituted about $8.9 \%$, which is almost consistent with the present study. In a study by Kaliaperumal Karthikeyan et $\mathrm{al}^{9}$, papular urticaria was seen in about $5.27 \%$. and in Manisha Balai et al ${ }^{10}$, papular urticaria constituted about $5.1 \%$. In the present study pigmentary disorders constitute about fifth common dermatoses. It is seen in about $4 \%$. In the present study, vitiligo was the most common pigmentary disorder noted. This was followed by freckles and Albinism. In a study by Saurabh sharma et $\mathrm{al}^{11}$, among pigmentary disorders vitiligo was most common, followed by freckles. In a study by Al-Mendalawi et $\mathrm{al}^{5}$, among the pigmentary disorders vitiligo was the most common disorder noted.

In the present study, sweat and sebaceous gland disorders constituted about 3.82\%. Among them Miliaria was most common, accounted for about $74 \%$ of sweat and sebaceous gland disorders and constituted about $2.8 \%$ of all dermatoses. In a study done by Iffat Hassan et $\mathrm{al}^{7}$, Miliaria was seen in $1 \%$. In study by Saurabh sharma et $\mathrm{al}^{11}$, sweat gland disorders constituted about $1.6 \%$ of cases. The higher rates of miliaria in the present study could be due to the increased temperature and humidity in the study area.

In present study Papulosquamous disorders accounted for $2.8 \%$, in Iffat Hassan et.al ${ }^{7}$.it was $1.8 \%$. In Kaliaperumal Karthikeyan et $\mathrm{al}^{9}$ it was $1.6 \%$ The higher rates of papulosquamous disorders in the present study could be attributed to the increased frequency of streptococcal sorethroat in these children and failure to get proper and complete treatment for the same. In present study lichenplanus was most common disorder seen, which accounted for about $42 \%$ of papulosquamous disorders.

In the present study nutritional dermatoses was seen in about $2.7 \%$. In a study conducted by Kaliaperumal Karthikeyan et $\mathrm{al}^{9}$, nutritional dermatoses were seen in about $2.8 \%$, which is in correlation with the present study. In present study, Phrynoderma was the most common nutritional disorder. Rita vora et $\mathrm{al}^{6}$, in his study also found that the Phrynoderma was the most common nutritional disorder which is consistent with present study.

In the present study Keratinisation disorders were seen in $2.4 \%$ patients. In study conducted by Kaliaperumal Karthikeyan et $\mathrm{al}^{9}$, and Manisha Balai et $\mathrm{al}^{10}$, Keratinisation disorders were noted in about $2.1 \%$ and $2.53 \%$, which is in correlation with present study. In a study by Saurabh sharma et $\mathrm{al}^{11}$, these disorders constituted about $1.1 \%$. The higher occurrence of these keratinisation disorders in present study could be explained by the fact that Government general hospital, Vijayawada is a referral centre.

In present study, most common photodermatoses was Polymorphic light eruption. It constituted about 2.3\%.In a study conducted by S Sacchidanand et $\mathrm{al}^{8}$, photodermatoses constituted about $2.5 \%$,which is consistent with the present study. In a study conducted by karthikeyan $\mathrm{K}$ et $\mathrm{al}^{9}$, the polymorphic light eruption was reported to be about $0.14 \%$. Compared to other studies, increased frequency of polymorphic light eruption in this part of the country could be attributed to increased sun intensity during summer.

In the present study, Nevi constituted about $2 \%$. In various studies reported by Negi et al, nevi range from 1.6 to $2.3 \%$, which is consistent with the present study. In a study conducted by Ruiz -Maldonado R et $\mathrm{al}^{13}$, they were reported in about $2.3 \%$, which is in correlation with present study. In present study, among nevi mongolian spot was most common. Senthil kumar et $\mathrm{al}^{14}$ in his study found out that Mongolian spots were the most common nevi, which is in correlation with present study.

In present study, Hair and nail disorders constitute about $1.5 \%$. In a study conducted by Iffat Hassan et $\mathrm{al}^{7}$, hair and nail disorders were seen in about $1.8 \%$ which is in correlation with the present study. In the present study most common hair disorder seen was Alopecia areata, followed by canities . Among the nail disorders paronychia was most commonly seen.

In present study, vesiculo bullous disorders constituted about $0.6 \%$ of all dermatoses. In study conducted by Manisha et $\mathrm{al}^{10}$, these disorders constituted about $0.58 \%$, which is consistent with present study. In study conducted by iffat Hassan et $\mathrm{al}^{7}$, vesiculobullous disoders constituted about $0.46 \%$ of cases which is in correlation with the present study. In present study, Epidermolysis bullosa simplex was the commonest followed by junctional type of Epidermolysis bullosa.

In present study, connective tissue diseases and disorders, constituted about $0.6 \%$ of all dermatoses. In a study conducted by Karthikeyan $\mathrm{K}$ et $\mathrm{al}^{9}$. they constituted about $0.5 \%$ of cases, which is in correlation with present study. Among collagen vascular disorders one case of Morphea and a one case of Dermatomyositis in a female child had been reported.

In present study, genodermatoses was seen in about $0.2 \%$. One case of Xeroderma pigmentosum in a nine year old boy had been recorded

\section{Conclusion}

The present study brings into light the unique features of Tropical pediatric dermatology such as high frequency of dermatoses like infections and infestations, Eczemas and environment associated disorders (insect bite reaction and miliaria).

The incidence of pediatric dermatoses can be brought down by increasing awareness among the 
population regarding etiology and spread of pediatric diseases and by improving sanitation, nutrition and personal hygiene of children.

This study provides a preliminary baseline data for future epidemiological and clinical research. It might also help to assess the changing trends of pediatric dermatoses.

It is important to determine the prevalence of skin disorders so that necessary educational programs and preventive measures can be performed. Health education and good personal hygiene will definitely help to improve the health status of school children.

\section{References}

[1]. Graham -Brown R.A.C - The ages of man and their dermatoses - Rook's Text book of Dermatology Tony burns, Stephen Breathnach, Neil cox, Christopher Griffith: 7th edition ;2004 70.1,Blackwell science publication.

[2]. Thappa DM. Common skin problems in children. Indian J Pediatr 2002;69:701-6.

[3]. Federman DG, Reid MC, Feldman SR et al. The primary care provider and the care of skin disease. Arch Dermatol2001;137:25-9.

[4]. J.of Paediatric dermatology (ISSN 0736-8046) Blackwell science, Ink, Malden: MA 021-48.

[5]. M. D. Al-Mendalawi 1 and J.G. Ibrahim.Pattern of dermatoses in Iraqi children. Eastern. Mediterranean Health Journal2012,vol(18) No.4-PP 365-77

[6]. Rita Vora, Nishit Bodiwala, Shivang Patel. Prevalence of various dermatoses in school children of Anand district. National Journal of Community Medicine Vol 3 Issue 1 Jan-March 2012 pp 100- 03.ISSN: 09763325 eISSN: 22296816.

[7]. Hassan I, Ahmad K, Yaseen A.Pattern of pediatric dermatoses in Kashmir valley: A Study from a tertiary care centre, Indian J Dermatol Venereol Leprol 2014,80;448-81.

[8]. Sacchidanand S, Sahana MS, Asha GS, et al. Pattern of Pediatric Dermatoses at a Referral Centre. The Indian Journal of Pediatrics April 2014; Volume 81, Issue 4, pp 375-380.

[9]. Kaliaperumal Karthikeyan, Devinder Mohan Thappa and B. Jeevankumar. Pattern of Pediatric Dermatoses in a Referral Center in South India. Indian Pediatrics 2004; volume 41:373-77.

[10]. Balai M, Khare AK, Gupta LK, Mittal A, Kuldeep C M. Pattern of pediatric dermatoses in a tertiary care centre of South West Rajasthan .Indian J Dermatol 2. 2012 Jul-Aug; 57(4): 275-278

[11]. Saurabh Sharma, Roopam Bassi, Manmeet Kaur Sodhi. Epidemiology of dermatoses in children and adolescents in Punjab, India Journal of Pakistan Association of Dermatologists 2012;22 (3):224-229.

[12]. Sardana K, Mahajan S, Sarkar R, Mendiratta V, Bhushan P, Konanne RV, et al. The spectrum of skin disease among Indian children. Pediatr Dermatol 2009;26:6-13.

[13]. Blanca Rosa Del Pozzo-Magana, Alejandro Lazo-Langner, Pedro Gutierrez-Castrellon, and Ramon Ruiz- Maldonado. Common Dermatoses in Children Referred to a Specialized Pediatric Dermatology Service in Mexico: A Comparative Study between Two Decades .ISRN Dermatology Volume 2012, Article ID 351603, 5pages.

[14]. Senthilkumar M, Thappa Devinder Mohan, Melanocytic nevi in children: A clinical study, Department of Dermatology \& STD, Jawaharlal Institute of Post graduate Medical Education and Research, Pondicherry - 605006. 